\title{
Investigating the Effective Bioclimatic Factors on Tourism Industry (Case of Study: Zanjan, Iran)
}

\author{
Behrouz Nasiri $^{1} \&$ Mina Mirian ${ }^{2}$ \\ ${ }^{1}$ Department of Natural Geography, Lorestan University, Khoramabad, Iran \\ ${ }^{2}$ Geographical Department, Lorestan University, Khoramabad, Iran \\ Correspondence: Behrouz Nasiri, Department of Natural Geography, Lorestan University, Khoramabad, Iran. \\ E-mail: behrouz.nasiri46@gmail.com
}

\author{
Received: January 17, 2016 Accepted: February 2, 2016 Online Published: March 18, 2016 \\ doi:10.5539/ass.v12n4p108 URL: http://dx.doi.org/10.5539/ass.v12n4p108
}

\begin{abstract}
The tourism industry is one of the largest and fastest growing economic factors in the contemporary worlds. Many factors affect the tourism industry; one of the most important of them is climate. Unfortunately, tourism literature has not paid much attention to the effect of climatic factors on the industry as it worth. Therefore, in order to develop this area of global economic, it is necessary to recognize the capabilities and limitations of the climate area. In this research, in order to evaluate environmental conditions in there, indicators of effective temperature (ET), temperature-humidity (THI), Baker Index (CP), and physiological stress indicators, $\left(\mathrm{P}_{\mathrm{phs}}\right)$ by using monthly statistic parameters of temperature, relative humidity wind and synoptic sampling stations during the period 2005 - 1955 are used. Results show that based on the parameters of ET, the maximum temperature in April, the minimum temperature in July and August and the average temperature can be seen in May. About THI index comfort conditions can be seen just in March and November and CP index indicates total bioclimatic comfort in summer. Index $\left(P_{p h s)}\right.$ also found that only the months of June, September and has been neutral in terms of biological stress.
\end{abstract}

Keywords: tourist region, effective temperature, baker, temperature-humidity, psychological pressure, Zanjan, Iran

\section{Introduction}

Tourism is one of the largest and fastest growing economic sectors (Hamilton et al., 2005). This industry with more than 760 million tourists and some 622 billion dollars in 2004 and 700 billion dollars in 2006, allocates about 10 percent of global GDP (Ataei et al., 2010, p. 28). World Tourism Organization has also predicted that by 2020 , the world population of tourists to one billion and its revenue to 6.1 billion dollars increases (WTO, 2006). Tourism is highly dependent on climate. So, it is surprising that tourism literature has paid little attention to climate and climate change (Hamilton et al., 2005). Although, most tourism studies focus on economic variables (Lim et al., 2008), climate is recognized as a driver key for tourism and as an important feature for destination (Hu and Ritchie, 1993). Also, climate is considered as a key resource for tourism (Kozak et al., 2008) or as a facilitator, which makes the tourism activities possible and enjoyable (Martin, 2005). Many factors affect the tourism industry, which climate is one of the most important of them. Along with geographic location, topography, vision, flora and fauna, climate as one of the most important local resource plays a role in the tourism industry. It can be said that the climate is an enormous natural wealth, which by impacting on environmental resources controls length and quality of tourism, health and even personal experiences of tourists (Tavousi \& Yari, 2013). Climate as one of the main components of natural systems affects tourism industry in different ways and in interaction with this industry it proposes a new discussion with name of tourism ecology. Studies of tourist ecology are in an overview connected with concepts of climate and tourism. Climate has the concept of air in it and is recognized as a set of daily and seasonal weather conditions and events in a long time. Tourism, which includes concept of entertainment, is defined as act of travelling for leisure and entertainment and leisure is optional activities for personal interests and pleasure (De Freitas, 2003). Climate has significant impact on tourist behavior and plays a role for choosing place of travel and activities (Lin \& Matzarakis, 2008). Leisure and tourist centers in both the past and present know their existence and values due to various factors including proper and gentle the weather conditions. On the other hand, bad weather conditions decreases the 
positive aspects and attractions of a tourist area and leaves adverse effects on tourism. Indication of each weather events can lead to disorder in tourism. The occurrence of storms and high winds may revolve blocking communication lines, such as air - land and sea and finally severe coastal breeze will create unpleasant conditions on sandy beaches, which create negative repercussions on tourism (Zadeh, 2008). The relationship between weather, climate and tourism is in different forms. On the one hand we are dealing with meteorological conditions that are very variable from one place to another and at intervals; on the other hand, tourism also is the multi-faceted phenomenon. Its interaction effects are a very complex and have made relationship between weather - climate - tourism issue as a very complex and controversial work. The main cause of the phenomenon of seasonal tourism is climate (Ataei et al., 2010). Tourism has been the biggest industry in the world, a fact that has been not mentioned in today's research (Lise \& Tol, 2002). Therefore, it is necessary to study and identify the limitations and risks of climatic threats and also to be aware of the potential attractions and natural features and climate of each region in different seasons of the year in order to use them in different planning. Zanjan City in Iran also by having unique natural and man-made tourist attractions Such as KataleKhor cave (the second largest limestone cave in the world), Dome of Soltaniyeh, The world's first salt man, Laundry etc. is suggested as one of the Tourist attraction centers in the country and the world. According to the climatic conditions in the North West of the Iran, including the Zanjan, traditionally usually in warm period of the year this city is selected for tourism. Snow, ice and cold weather in cold period of year is usually considered as the main obstacle for tourism. This study was aimed to survey terms of climatic comfort by using several bioclimatic indexes. Results of this study can be used in setting time for the implementation of tourism programs and planning to increase the quantity and quality of tourism services by Organizations and agencies.

\section{Research Background}

In field of climate - tourism and the impact of weather conditions on human comfort many studies have been done up to now around the world. Achieving climate comfort conditions in each country is empirically possible, dependent on its climate conditions, but scientific study and documented climatic conditions and comfort of human goes to late 50's and 60 twentieth century. Ashrae Research Center in the years $1925-1923$ provided the effective temperature coefficient ET, which is raised from combination of three climate elements, humidity, temperature and wind conditions, through which the climatic conditions for human well-being can be calculated. Olgii was the first one, who presented a bioclimatic chart in 1963 and scientifically provided humidity and heat conditions in relation to human needs and climatic design. Tarjoung has in 1966 categorized bioclimatic areas of the United States of America based on convenience factor and the cooling effect of the wind. Baker (2000) has studied climatic conditions of 31 cities of South Africa's with regard to thermal feeling of the people from circumstance and came to the conclusion that maximum comfort conditions can be found in the Mediterranean region around Cape Town reigns. Ogunsote (2003) has begun to choose thermal index for architectural design with the climate in Nigeria. Hamilton (2005), by using a simulation model examined climate change and the International Tourism and also has analyzed base effects of population, capita income and climate change on entry and exit and this led to the conclusion that the impact of climate change is smaller than two other parameters. Lin and Matzarakis analyzed Climate - Tourism and thermal comfort index in Taiwan using physiological equivalent temperature. Dili et al. (2010) studied thermal comfort of residential buildings in the traditional Kerala using a questionnaire survey among residents of traditional and modern buildings. Also Weitz and Richard (2002) have been studied the climate impact on the tourism industry. In Iran, also several studies have been conducted in the field of tourism climate and climatic comfort, which are presented in following:

Kaviani (1992) using Baker equation has obtained the map of bioclimatic summer and winter for the northern and southern of Iran. In 1993 during a comprehensive survey entitled "Survey and Mapping Environment Iranian human climate" has provided Humidity, sunshine, wind efficacy, Tarjoung convenience factor and relevant charts and comfort index for January and July in Iran. Jahanbakhsh (1998) evaluated the scope of human bioclimatic provocations in Tabriz by Baker method. Zolphagharieh (2007) studied a suitable calendar for circulation in Tabriz, using indicators of physiological equivalent temperature (PET) and the average poll forecast (PMV). Mohammadi and Saeedi (2009) examined the comfort or discomfort of people in the city of Qom, Iran, based on bioclimatic models and indicators of Baker, Tarjoung, stress and Term hygrometric and came to the conclusion that area over the years in terms of bioclimatic conditions has incredibly hot to very cold climate. Bazrpash and Maleki (2008) in order to assess climatic condition of Babolsar, Iran in terms of outdoor thermal comfort for ecotourism offered a range of thermal comfort and optimum conditions for tourism in nature and open space from April to late October. Hezarkhani (2008) reviewed and analyzed climate - Tourism in Qom, using indices, which is related to human comfort, thermal stress and psychological pressure. Parvane et al. (2011) studied the determination of climatic comfort on a scale of decades based on the bioclimatic factors in 
Aligoudarz city of Iran. The results showed that by observing principles of architectural harmonic with the climate there is no need for cooling equipment during the year.

\section{Area of Study}

Province Zanjan of Iran with an area of about 22164 square kilometers, between 35 degrees and 37 minutes to 37 degrees 15 minutes of north and 47 degrees 10 minutes to 49 degrees and 25 minutes of east latitude is located in north-western of Iran. This province is limited from north to Ardabil, from west to West Azerbaijan Province, from south to Hamedan province and from east to Qazvin (Management and Planning Organization, 2004). City of Zanjan is one of the cities of the eastern part of Zanjan province, which is located on the route of Tehran Tabriz with average height of 1663 meters above sea level. This city is located in orbits 48 degrees and 14 minutes to 48 degrees 44 minutes east longitude and 36 degrees 39 minutes to 36 degrees 42 minutes north latitude (Ahadnejad Roshti, 2009) and among a series of mountains to the north, North East, South and South-West (Pour Mohammadi et al., 2008).

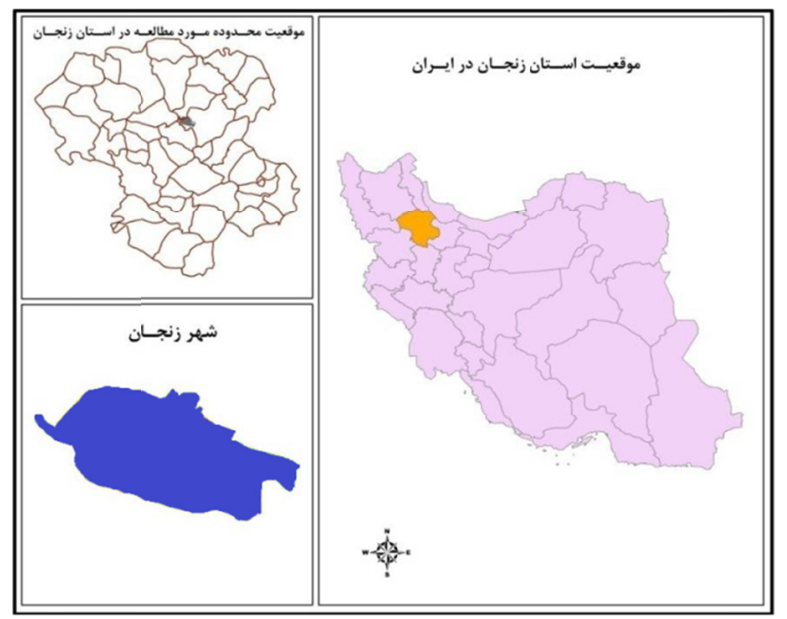

Figure 1. Geographical situation of area of study

\section{Materials and Methods}

To study the climatic conditions of the region, the comfort index has been used. Comfort indicators are diagrams and tables, which show the collective impact of all affecting factors on the feeling of comfort. The thermal index can be used to assess the tourism situation to aware tourists of the climatic conditions and to specify climatic tourism potential in different regions (Gandomkar, 2011). In this research, in order to evaluate environmental conditions in the area, indicators of effective temperature (ET), temperature-humidity (THI), Baker Index (CP), and physiological stress indicators $\left(\mathrm{P}_{\mathrm{phs}}\right)$ by using monthly statistical parameters of temperature, relative humidity wind and synoptic sampling stations during the period $2005-1955$ are used.

Table 1. Comfort factor for effective temperature

\begin{tabular}{cc}
\hline Effective temperature ET & Comfort Factor \\
\hline$>30$ & Very hot \\
$27.6-30$ & Sultry \\
$25.6-27.6$ & Very warm \\
$22.2-25.6$ & Warm \\
$17.8-22.2$ & Comfort \\
$15.5-17.8$ & Cool \\
$1.67-15.5$ & Very cool \\
$-10-1.67$ & Cold \\
-20 to -10 & Very cold \\
$<-20$ & Very cold \\
\hline
\end{tabular}


Index effective temperature ET: The most accurate indicator, which has been presented for review climatic conditions from the perspective of human comfort, is the effective temperature. This scale was presented for the first time by Yaglou and Houten in cooperation with Ashrea Company in 1923 USA. The effective temperature is the temperature of saturated still air that can have the same effect as desired air without any radiation (Kotinsburg, 1989). Houtan or Yaglou define the effective temperature as follow: temperature in a standardized environment with relative humidity of $50 \%$ wind speed $(\mathrm{V})$ of less than 0.5 meters per second and the air temperature is equal with the radiation temperature $(\mathrm{ta}=\mathrm{tr})$, so that a person experiences the same temperature that is experienced in the real environment (Kaviani et al., 2006). To calculate the effective temperature following formula is used (1):

$$
E T=t+0.4(t+1)(1-R H / 100)
$$

In which $E T\left({ }^{\circ} \mathrm{C}\right)$ effective temperature $t\left({ }^{\circ} \mathrm{C}\right)$ is environmental temperature and $\mathrm{RH}$ is Relative humidity.

Temperature - humidity Index THI: this index is mainly called index of human comfort, which was presented for the first time in 1959 in order to assess the summer situation in USA and it is a combination of temperature and humidity. Temperature - humidity Index is defined as the degree of discomfort felt by a typical worker. Therefore, aspects of radiation and air flow are not intended. Following amended equation is provided to directly calculate the index using dry and wet temperature in Celsius.

$$
\mathrm{THI}=0.72(\mathrm{Td}+\mathrm{Tw})+40.6
$$

Table 2. Classification of temperature humidity index

\begin{tabular}{ll}
\hline Range of temperature humidity index & Classification of feeling heat \\
\hline Less than 50 & Feeling cold \\
$50-60$ & Relatively cold \\
$60-70$ & Comfort \\
$70-75$ & Relatively uncomforted \\
$75-80$ & uncomforted \\
80 and more & Very uncomforted \\
\hline
\end{tabular}

Baker bioclimatic index CP: Baker using some climatic elements, such as average wind speeds at a height of 2 meters and average daily temperature has calculated the cooling power $(\mathrm{CP})$ and earned the bioclimatic situation of region. Baker believes that various climatic factors influence the human organism and reactions to that are different. Thus it is possible to have a correct assessment of the extent of bioclimatic stimulation, when detailed analysis of the organism reactions is available. Because between all significant elements related with bioclimatic stimulation of human, cooling power, which is a combination of temperature and humidity, is more suitable than all other elements. Baker has used following equation to calculate the cooling power $(\mathrm{CP})$ :

$$
\begin{aligned}
& C P=\left(0.26+0.34 \times V^{0.632}\right) \\
& \times(36.5-t) \mathrm{mcal} / \mathrm{cm}^{2} / \mathrm{sec}
\end{aligned}
$$

In which $\mathrm{V}$ is velocity of wind (meter per second) and $\mathrm{T}$ is average daily temperature.

In this equation cooling power is represented according to different between human body temperature and environment temperature. Baker has defined degree of environmental cooling power and threshold of bioclimatic stimulation of human in following table:

Table 3. Degree of environmental cooling power and threshold of bioclimatic stimulation of human

\begin{tabular}{ccc}
\hline Value of CP & Environment condition & Human bioclimatic condition \\
\hline $0-4$ & Hot, humid and unpleasant & Bioclimatic pressure \\
$5-9$ & Tolerable heat & Zone bioclimatic comfort \\
$10-19$ & Pleasant and mild & Zone of bioclimatic comfort \\
$20-29$ & Cool & Mild stimulation \\
$30-39$ & Cold a little pressure & Average to serve stimulation \\
$40-49$ & Very col & Averagely pressure \\
$50-59$ & Unpleasant cold & Firmly pressure \\
\hline
\end{tabular}


Physiological pressure index: The index shows roughly (with error less than 0.10 ) the intensity of physiological pressure on the human body, as a result of changes in temperature of environment and is calculated using amended equation of Blasi about thermal interaction between human and environment with MENEX -2002 model. It is only necessary to calculate the parameters of air temperature. This index based on the intensity is divided into 7 categories. Accordingly, if the calculated value is below zero, thermal pressure is high and if its value reaches to 8 the thermal pressure is very low.

$$
P_{p h s}=(2.12513-0.058018 t)^{2}
$$

Table 4. Classification of pressure on human

\begin{tabular}{cc}
\hline Classification of pressure on human & $P_{p h s}$ \\
\hline Too high thermal pressure & Blew zero \\
High thermal pressure & $0-0.24$ \\
Average thermal pressure & $025-0.74$ \\
Neutral state & $0.75-1.5$ \\
Average cooling pressure & $1.51-4$ \\
High cooling pressure & $4.1-8$ \\
Too high cooling pressure & More than 8 \\
\hline
\end{tabular}

\section{Results and Discussion}

Effective temperature Index ET: Table 5 shows the effective temperature index values (ET) for Zanjan, Iran stations in different months of the year. As table indicates the lowest average of effective temperature for maximum temperature parameter in January Zanjan city is 3 degree Celsius, which according to table (1) expresses the very cool comfort factor. Also, the highest average of effective temperature for maximum temperature parameter is 39.8 degree Celsius in August and expresses very warm comfort factor (lack of comfort). As we can see, with the exception of April, other months have the conditions of thermal comfort. The lowest average of effective temperature for minimum temperature parameter is -8.2 degree Celsius in January and the highest average of effective temperature in 18.4 degree Celsius in July, which respectively represents cold comfort factor and thermal comfort. As it is shown, for this parameter, the two months of July and August have the conditions of thermal comfort. Also the lowest average of effective temperature for average temperature parameter is -2.8 in January and the highest temperature is 30.4 in July, which indicates cold and very warm comfort factor. Only May has the climatic comfort situation.

Table 5. Values of effective temperature in different month of ear in Zanjan, Iran

\begin{tabular}{cccc}
\hline & Maximum temp & Minimum temp & Average temp \\
\hline J & 3 & 8.2 & 2.8 \\
F & 5.4 & 6.6 & 0.6 \\
M & 12 & 1.3 & 5.6 \\
A & 20.5 & 4.8 & 13 \\
M & 27.3 & 9.2 & 19.2 \\
J & 35.5 & 13.9 & 26.2 \\
J & 39.7 & 18.4 & 30.4 \\
A & 39.8 & 18 & 30.1 \\
S & 35 & 12.4 & 24.7 \\
O & 24.8 & 6.7 & 16 \\
N & 14.3 & 0.7 & 7.4 \\
D & 6.4 & 4.5 & 0.7 \\
\hline
\end{tabular}




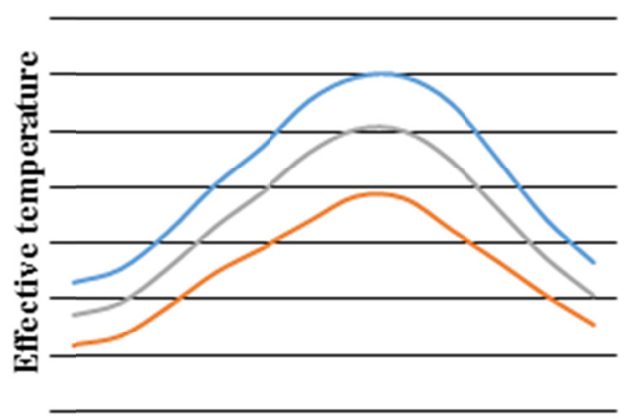

Maximum tempreture

Temperature humidity index THI: Based on calculations from temperature - humidity (THI) formula, the climatic comfort situation in Zanjan station in twelve months are as follow:

1) In January, February and December climate is outside the comfort range, and situation is cold.

2) In March and November, there is comfort condition.

3) In April, May, June, July, August, September and October situation is very uncomfortable.

Table 6. Values of THI in different month of ear in Zanjan, Iran

\begin{tabular}{cc}
\hline Month & THI \\
\hline J & 21.8 \\
F & 37.9 \\
M & 68.36 \\
A & 105.4 \\
M & 134.6 \\
J & 165.48 \\
J & 18.6 \\
A & 185.8 \\
S & 154.96 \\
O & 119.49 \\
N & 67.4 \\
D & 38 \\
\hline
\end{tabular}

Baker bioclimatic index (CP): According to Baker's review, if CR levels are less than 5 or more than 20 then we have bioclimatic pressure. In the first case due to the high temperature an unpleasant situation occurs. In the second case because of the cold ambient we have discomfort conditions. Using the 50-year climate data of Zanjan stations and using baker equation, the cooling power in different months of year in Zanjan is calculated and in Table 7 represented.

Table 7. Values of CP in different month of ear in Zanjan, Iran

\begin{tabular}{cc}
\hline Month & $\boldsymbol{C P}$ \\
\hline J & 36.8 \\
F & 34.6 \\
M & 30.3 \\
A & 29.4 \\
M & 18.7 \\
J & 14.8 \\
\hline
\end{tabular}




\begin{tabular}{cc}
\hline Month & $\boldsymbol{C P}$ \\
\hline $\mathrm{J}$ & 12.3 \\
$\mathrm{~A}$ & 12.5 \\
$\mathrm{~S}$ & 15.4 \\
$\mathrm{O}$ & 20.3 \\
$\mathrm{~N}$ & 27.3 \\
$\mathrm{D}$ & 33.3 \\
\hline
\end{tabular}

According to values of Table 7, year trend graph of Zanjan bioclimatic stimulation is drawn in Figure 1, as Figure 1 shows in winter the $\mathrm{CP}$ content of more than 30 micro-calories per square centimeter per second, indicating cold environmental conditions and a bit of pressure and human bioclimatic conditions with moderate to severe irritation during the season. In the spring CP content gradually reduces (average 12) and conditions from cold and low pressure in winter changes to mild and pleasure to cool condition, which indicates the relative scope of bioclimatic comfort in this area. During the summer environmental cooling power decreases up to 12 micro-calories. And by coming fall the environmental cooling power increases and condition changes to state of mild, moderate or severe bioclimatic situation $(\mathrm{CP}=27)$.

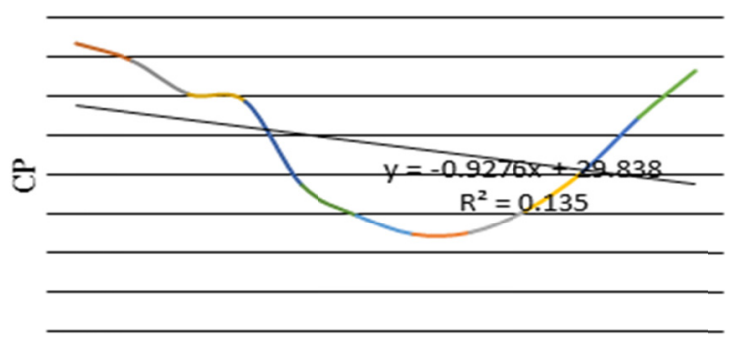

Month

Figure 2. Annual trend graph of Zanjan bioclimatic stimulation

Physiological pressure index: According to calculation of this index following results are represented:

1) In July and August we have medium heat pressure.

2) In June, September and May we have a neutral situation which shows insignificant thermal pressure. 3) In March, April, October and November there is average thermal pressure.

4) January, February and December are associated with high thermal pressure

Table 8. Values of $\boldsymbol{P}_{\boldsymbol{p h s}}$ in different month of ear in Zanjan, Iran

\begin{tabular}{cc}
\hline Month & $\boldsymbol{P}_{\boldsymbol{p h s}}$ \\
\hline J & 18 \\
F & 4.66 \\
M & 3.43 \\
A & 2.22 \\
M & 1.44 \\
J & 0.81 \\
J & 0.5 \\
A & 0.52 \\
S & 0.96 \\
O & 1.84 \\
N & 3 \\
D & 4.39 \\
\hline
\end{tabular}




\section{Conclusion}

Attention to the characteristics and potential of climate can be more effective in order to take advantage of spatial abilities and to achieve sustainable development. Climate of one area effects tourism industry as an important economic dimension from various aspects. This affect has two negative and positive dimensions. Understanding or lack of understanding of climate patterns of an area can play a big role in motivating tourists. Thus, this study aimed to distinguish some suitable months, which have good feeling for tourists, based on some bioclimatic index. Results can be represented as follow:

Calculations based on the effective temperature index shows that maximum temperature parameter except April has uncomfortable situation in other months. In minimum temperature parameter two months of July and August and in average temperature parameter May have the bioclimatic comfort situation.

Calculations based on the temperature humidity index shows that some month have equal situation and comfort condition can just be seen in November and March.

Using baker index about environmental cooling power it is resulted that June, July, August and September, are in bioclimatic comfort zones and during year only summer has bioclimatic comfort situation.

Biological pressure index also showed that there is in July and August, average thermal pressure and in April, March, October and November, average cooling pressure. And July and September have neutral situation.

\section{References}

Ahadnejad Roshti, M. (2009). Modeling of earthquake vulnerability assessment (Case of Zanjan City) (p. 174). Dissertation geography and urban planning. Tehran University.

Amelung, B., Nicholls, S., \& Viner, D. (2007). Implications of Global Climate Change for Tourism Flows and Seasonality. Journal of Travel Research, 45(3), 285-296. http://dx.doi.org/10.1177/0047287506295937

Ataei, H., \& Hashemi Nasab, S. (2010). Study of climatic tourist potential of Semnan using Physiological Equivalent Temperature index (PET). Geography and Regional Planning, 2, 28.

Barimani, F., \& EsmaeilNezhad, M. (2011). Bioclimatic indices influencing the tourism season: The southern part of Iran. Journal of Geography and Development, 23, 27-46.

Bazrpash, R., \& Maleki, H. (2008). Outdoor thermal comfort for ecotourism in the city of Babolsar. Geographical study, 90, 93-108.

De Freitas, C. R. (2003). Tourism climatology: evaluating environmental information for decision making and business planning in the recreation and tourism sector. Int. J. Biometeorol, 48, 45-54. http://dx.doi.org/10. 1007/s00484-003-0177-z

Dili, A. S., Naseer, M. A., \& Zacharia Varghese, T. (2010). Thermal comfort study of Kerala traditional residential buildings based on questionnaire survey among occupants of traditional and modern buildings. Energy and Buildings, 42(11), 2139-2150. http://dx.doi.org/10.1016/j.enbuild.2010.07.004

Gandomkar, A. (2011). Determining the city of Nain Tourism Climate Index with the use of GIS. Journal of Human Geography, 3, 94.

Gómez Martín, M. A. (2005). Weather, Climate and Tourism.A Geographical Perspective. Annals of Tourism Research, 32(3), 571-591. http://dx.doi.org/10.1016/j.annals.2004.08.004

Hamilton, J. M., Maddison, D. J., \& Richard S. J. (2005). Climate change and international tourism: A simulation study. Global Environmental Change, 15, 253-266. http://dx.doi.org/10.1016/j.gloenvcha.2004. 12.009

Hu, Y., \& Ritchie, J. (1993). Measuring destination attractiveness: A contextual approach. Journal of Travel Research, 32(20), 25-34.

Jahanbakhsh, S. (1998). Human bioclimatic assessment of Tabriz and thermal needs of the building. Geographical Research Quarterly, 48, 79-67.

Kaviani, M. (1993). Survey and mapping of the human-friendly climate. Geographical Research Quarterly, 48, 80.

Kotinsburg, O. H. (1989). Climatic design guide (Translator M. Kasmaee). Ministry of Housing, Tehran.

Kozak, N., Uysal, M., \& Birkan, I. (2008). An analysis of cities based on tourism supply and climatic conditions in Turkey. Tourism Geographies, 10(1), 81-97. http://dx.doi.org/10.1080/14616680701825230 
Lim, C., Min, J. C. H., \& McAleer, M. (2008). Modelling income effects on long andshort haul international travel from Japan. Tourism Management, 29(6), 1099-1109. http://dx.doi.org/10.1016/j.tourman.2008. 02.012

Lin, T. P., \& Matzarakis, A. (2008). Climate-tourism Analysis and Application of Tourists Flow Forecast in Taiwan. ICB, Tourism, Symposium.

Management and planning of the province. (2004). Department of Statistics and Information, Statistical Yearbook of Zanjan province.

Muhammadi, H., \& Saeedi, A. (2008). Effective climate-friendly indicators to measure human welfare case study: the city of Qom. Journal of Ecology, 47, 73-86.

Ogunsote, O. O. (2003). Choice of a thermal index for architectural design with climate in Nigeria. Habitat International, 27(1), 63-81. http://dx.doi.org/10.1016/S0197-3975(02)00035-8

Pour Mohammadi, M., Jamali, F., \& Asghari, A. (2008). Spatial evaluation of development of the cities with emphasis on the land use change. Geographic Studies, 63, 29-46.

Tavousi, T., \& Yari, M. (2013). Determine the range of thermal comfort in the planning of tourism Province: Sistan and Baluchestan Province. Journal of Geography and Development, 31, 29-26.

Zolfagharieh, H. (2007). Setting calendar for circulation in Tabriz by conducting physiological equivalent temperature (PET) and average poll forecast (PMV). Geographic Studies, 62, 129-141.

\section{Copyrights}

Copyright for this article is retained by the author(s), with first publication rights granted to the journal.

This is an open-access article distributed under the terms and conditions of the Creative Commons Attribution license (http://creativecommons.org/licenses/by/3.0/). 